\title{
A case of an uncorrected double outlet right ventricle with ventricular septal defect in pregnancy
}

\author{
Kedar M. Tilak ${ }^{1 *}$, Uma N. Wankhede ${ }^{2}$
}

\author{
${ }^{1}$ Department of Pediatrics, PGI-YCM Hospital, Pune, Maharashtra, India \\ ${ }^{2}$ Department of Obstetrics and Gynaecology, Sassoon General Hospitals, Pune, Maharashtra, India
}

Received: 20 July 2019

Accepted: 14 August 2019

\author{
*Correspondence: \\ Dr. Kedar M. Tilak, \\ E-mail: kedartilak28@gmail.com
}

Copyright: (c) the author(s), publisher and licensee Medip Academy. This is an open-access article distributed under the terms of the Creative Commons Attribution Non-Commercial License, which permits unrestricted non-commercial use, distribution, and reproduction in any medium, provided the original work is properly cited.

\begin{abstract}
Congenital Heart Diseases (CHD) lead to various changes in the normal mechanisms of hemodynamics. Pregnancy in women with CHDs is rare. Double Outlet Right Ventricle (DORV) is a rare disorder, in which both the aorta and the pulmonary artery arise from the right ventricle. We present a case of a thirty-year-old pregnant woman who presented to us with 22 weeks of amenorrhea. She had DORV with VSD, which was undiagnosed till she came to our hospital. Double Outlet Right Ventricle (DORV) is a rare congenital heart disease. Pregnancy in a patient with DORV needs early diagnosis and a stepwise multidisciplinary approach for successful outcomes.
\end{abstract}

Keywords: DORV, Heart disease, Pregnancy, VSD

\section{INTRODUCTION}

Recent breakthrough advances in pediatric cardiac surgery in the field of congenital heart disease (CHD) have resulted in an improved prognosis of $\mathrm{CHDs}$ especially in complex lesions., ${ }^{1,2}$ This has led to more number of women with congenital heart disease surviving into adulthood. They are likely to be affected by some complications when they get pregnant. ${ }^{1,2}$ There are a number of physiological changes in the hemodynamics of pregnant women. The outcome of pregnancy in women with congenital heart disease is variable. Although death is rare, there are a variety of maternal and fetal complications that may arise. Infants are at 3-50\% risk for developing some form of congenital abnormality. ${ }^{3}$ The antenatal management in these patients needs early preconception risk stratification. Patients with low risk need routine obstetric care and endocarditis prophylaxis. ${ }^{3}$ Patients with high-risk should be counselled to avoid pregnancy, however if they get pregnant, more stringent monitoring with ample bed rest is needed. Serial ultrasonography should be offered routinely.

The incidence of heart disease in pregnancy is between $0.4-4.1 \%$ with congenital heart disease being the most predominant one. ${ }^{4}$ DORV is characterized by a malformation, in which both that aorta and the pulmonary artery arise from the right ventricle. It always coexists with a ventricular septal defect (VSD). ${ }^{5}$ Double-outlet right ventricles (DORV) is an extremely rare congenital heart disease with an incidence of about $0.5-0.8$ per 10,000 births. ${ }^{6}$ We are presenting a case of a 30-year-old pregnant woman with uncorrected DORV with VSD.

\section{CASE REPORT}

We present a thirty-year-old patient who presented to our emergency room with severe breathlessness with recurrent hemoptysis. The patient had amenorrhea for 22 weeks. She couldn't recall the date of her last menstrual 
period and hence the expected delivery date (EDD) could not be calculated. The patient was $160 \mathrm{cms}$ in height with a weight of $61 \mathrm{kgs} \quad(\mathrm{BMI}=23.82)$. The patient also complained of decreased fetal movements for the past two days.

Table 1: Modified Fuwai classification for DORV. ${ }^{9}$

\begin{tabular}{|llll|}
\hline $\begin{array}{l}\text { DORV } \\
\text { subtype }\end{array}$ & $\begin{array}{l}\text { Relative position of the } \\
\text { great arteries }\end{array}$ & $\begin{array}{l}\text { Relationship between VSD and } \\
\text { great arteries }\end{array}$ & $\begin{array}{l}\text { Right ventricular outflow tract } \\
\text { obstruction }\end{array}$ \\
\hline IA & Normal & Committed & Absent \\
\hline IB & Normal & Committed & Present \\
\hline IIA & Normal & Non-committed & Absent \\
\hline IIB & Normal & Non-committed & Present \\
\hline IIIA & Abnormal & Committed & Absent \\
\hline IIIB & Abnormal & Committed & Present \\
\hline IVA & Abnormal & Non-committed & Absent \\
\hline IVB & Abnormal & Non-committed & Present \\
\hline
\end{tabular}

The patient had a history of two abortions. The first one was three years back at 18 weeks of gestation and the second one was one year back at 15 weeks of gestation. She did not seek any medical help at those times and both her abortions were done at a primary health center in her village. The present pregnancy was her third pregnancy. She said that she never had the present symptoms before and was asymptomatic in this pregnancy until she suddenly started having difficulty in breathing and complained of labored breathing since morning. Physical examination of the patient revealed her to be in moderate distress with central and peripheral cyanosis along with orthopnea. She was afebrile with a temperature of $98.3 \mathrm{~F}$, heart rate of 88 per minute and a blood pressure of $100 / 70 \mathrm{~mm} \mathrm{Hg}$. Her pulse oxygen saturation was $78 \%$. Her electrocardiogram was normal with slight evidence of right ventricular hypertrophy.

A chest radiograph was done and it showed slight cardiac enlargement. An Echocardiogram was done on the patient which showed these findings: Aorta overriding the ventricular septum, both aorta and pulmonary artery arising from right ventricle and both of normal size, large misaligned VSD of size $27 \mathrm{~mm}$ with bidirectional shunt, pulmonary gradient-120mmHg, good size and confluent pulmonary stenosis, normal biventricular function, left Ventricular Ejection Fraction was $60 \%$ with increased diameters of the right atrium and right ventricle.

On physical examination of the patient, there was respiratory distress with bilateral crepitation, an ejection systolic murmur on heart auscultation. Her New York Heart Association (NYHA) functional class was III-IV. CNS exam was normal. On examination of the abdomen, the patient had pain on palpation. The uterus was a size of 22 weeks. No fetal heart sounds could be auscultated and an ultrasonography revealed intrauterine death of the fetus. There was no discharge from the vagina.
Blood investigations revealed a hemoglobin level of 7 $\mathrm{g} / \mathrm{dL}$, a total leukocyte count of $7,400 / \mathrm{mm}^{3}$ and an adequate platelet count. The coagulation profile was normal. Total serum proteins and albumin levels were within the normal range. Rest of the blood chemistry, liver profile and renal profile were found to be within normal limits. The patient was given blood transfusion and peripheral fluid resuscitation. The woman was immediately shifted to the operating room and a hysterotomy was done to remove the dead fetus. The patient was the shifted to Obstetric ICU for observation. She was stabilized on fluids, oxygen and antibiotics before discharge She was counseled regarding cardiac surgery and future pregnancies.

\section{DISCUSSION}

The Society of Thoracic Surgeons and the European Association of Cardiothoracic Surgery have classified DORV into four different types. ${ }^{7,8}$ The types of DORV as per the Modified Fuwai Classification are summarized in Table 1.

In our case, the patient had a sub-aortic VSD (ventricular septal defect) with mild pulmonary stenosis. Because of the proximity of the VSD to the aorta, most of the oxygenated blood was ejected directly into the aorta. The oxygen saturation in this case depends on the amount of deoxygenated blood that is ejected from the right ventricle into the aorta. As with any patient with a large VSD, the pulmonary over circulation will give rise to pulmonary hypertension progressing to heart failure. DORV is mostly detected in early childhood due to repeated episodes of cyanosis and symptoms of congestive cardiac failure. DORV is an extremely rare congenital heart disease and cases of pregnancy with uncorrected DORV are even rarer. Even while reviewing literature, we came across very few reported cases pertaining to uncorrected DORV in pregnancy. Our 
patient was apparently all right till the day she presented to our hospital at 22 weeks of gestation. Her Echocardiogram did not show any evidence of pulmonary hypertension. We assumed that she had a well-balanced pulmonary and systemic circulation. The hemoptysis and dyspnea were due to her decompensating heart.

Our patient had an overriding aorta, right ventricular hypertrophy, mild pulmonary stenosis and VSD that is a picture quite similar to Fallot's tetralogy. The chronic hypoxic condition in these patients is responsible for causing polycythemia, increased viscosity of blood, and increased risk of thromboembolism. The increased oxygen demand in these patients overwhelms the hemodynamic adaptations in pregnancy and hence there are increased incidences of fetal losses in these patients.

The complications of congenital heart disease in the pregnant woman include spontaneous abortions, stillbirths, preterm births, intra uterine growth retardations and infective endocarditis. ${ }^{10,11}$ The most significant risk factor for adverse fetal outcomes is the extent of cyanosis. A hematocrit above $65 \%$ is almost always leads to fetal loss. ${ }^{12}$ In our patient, the NYHA IIIIV class cardiac failure along with cyanosis were other responsible risk factors to increase complications in the mother and the newborn.

The outcomes in these patients largely depend on the type of cardiac lesion, time of detection and the general well being of the woman with the lesion. A lot needs to be thought about the type of anesthesia in these patients during their delivery. An epidural anesthesia was given as the drugs used for general anesthesia might affect the already depressed cardiac function. ${ }^{8}$ These patients need to be monitored right from before conception and followed throughout their pregnancy. The usual course of surgery in these patients is a biventricular repair wherein the aorta is connected to the left ventricle followed by creating an intra-cardiac or extra-cardiac route to connect the pulmonary artery and the right ventricle at 4-6 months of age. ${ }^{10,13}$ A multidisciplinary approach involving an obstetrician, anesthesiologist, cardiologist pediatrician and cardiothoracic surgeon are necessary to achieve a good outcome.

\section{CONCLUSION}

To conclude, as of today, there is no definitive treatment for pregnant women with uncorrected DORV. Early diagnosis and proper counseling are keystones for a successful pregnancy outcome.

\section{Funding: No funding sources}

Conflict of interest: None declared

Ethical approval: Not required

\section{REFERENCES}

1. Fesslova VM, Villa L, Chessa M. Prospective evaluation from single centre of pregnancy in women with congenital heart disease. Int $\mathbf{J}$ Cardiol. 2009;131:257-64.

2. Sawhney H, Suri V, Vasishta K. Pregnancy and congenital heart disease-maternal and fetal outcome. Aust NZ J Obstet Gynaecol. 1998;38(3):266.

3. Stout K. Pregnancy in women with congenital heart disease: the importance of evaluation and counseling. Heart. 2005;91(6):713-4.

4. McFaul PB, Dornan JC, Lamki H, Boyle D. Pregnancy complicated by maternal heart disease. A review of 519 women. Br J Obstet Gynaecol. 1988;95(9):861-7.

5. Lev M, Bharati S, Meng CC, Liberthson RR, Paul MH, Idriss F. A concept of double-outlet right ventricle. J Thorac Cardiovasc Surg. 1972;64(2):271-81.

6. Pradat P, Francannet C, Harris JA, Robert E. The epidemiology of cardiovascular defects, part I: a study based on data from three large registries of congenital malformations. Pediatr Cardiol. 2003;24(3):195-221.

7. Walters HL, Mavroudis C, Tchervenkov CI, Jacobs JP, Lacour-Gayet F, Jacobs ML. Congenital heart surgery nomenclature and database project: double-outlet right ventricle. Ann Thorac Surg. 2000;69(4 Suppl):S249-63.

8. Gu J, Cai Y, Liu B, Lv S. Anesthetic management for cesarean section in a patient with uncorrected doubleoutlet right ventricle. Springerplus. 2016;5:415.

9. Pang KJ, Meng $\mathrm{H}, \mathrm{Hu}$ SS. Echocardiographic classification and surgical approaches to double-outlet right ventricle for great arteries arising almost exclusively from the right ventricle. Tex Heart Inst J. 2017;44(4):245-51.

10. Madhavi, Panchbudhe S, Mali K, Satia MN. Uncorrected double outlet right ventricle with Fallot's physiology in pregnancy. JPGO. 2015;2:6.

11. Presbitero P, Somerville J, Stone S, Aruta E, Spiegelhalter D, Rabajoli F. Pregnancy in cyanotic congenital heart disease: outcome of mother and fetus. Circulation. 1994;89:2673-6.

12. Cardiovascular Disorders. In F. Gary Cunningham FG, Leveno KJ, Bloom SL, Spong CY, Dashe JS, Hoffman BL, Casey BM, Sheffield JS, editors. Williams Obstetrics. $24^{\text {th }}$ ed. New York: McGraw-Hill Education; 2014:973-999.

13. Raisky O, Vouhé PR. Pitfalls in repair of conotruncal anomalies. Thoracic Cardiovascular Surgery Pediatric Cardiology Surgery Annual. 2013;16:7-12.

Cite this article as: Tilak KM, Wankhede UN. A case of an uncorrected double outlet right ventricle with ventricular septal defect in pregnancy. Int $\mathbf{J}$ Reprod Contracept Obstet Gynecol 2019;8:3805-7. 